Lepr Rev (2001) 72, 302-310

\title{
Studies on mode of detection of leprosy in China during the years 1981-1998
}

\author{
XIANG-SHENG CHEN*, WEN-ZHONG LI*, \\ CHENG JIANG*, CHENG-BIN ZHU* \& GAN-YUN YE* \\ Institute of Dermatology, Chinese Academy of Medical Sciences \\ (CAMS) \& Peking Union of Medical College (PUMC), National \\ Center for STD and Leprosy Control, 12 Jiangwangmiao Street, \\ Nanjing, 210042, China
}

\section{Accepted for publication 16 July 2001}

\begin{abstract}
Summary Along with the nationwide economic reform initiated in the early 1980s and the rapid decrease of leprosy endemic after the implementation of multi-drug therapy (MDT), the leprosy programme changed from 'vertical' to 'horizontal'. An evolution in the mode of detection of leprosy cases has consequently taken place. Based on the nationwide registration of newly detected cases, the profile of patients at detection has been studied. The proportions of cases corrected significantly with calendar years in detection by dermatological clinics, contact checks, 'clue survey' and mass survey, showing a significant increase in percentage of cases detected through dermatological clinics and contact checks, and decreases through 'clue survey' and mass survey. Detection of cases through dermatological clinics and voluntary reporting have become the main modes of case-finding during 1997-1998, accounting for $37.3 \%$ and $28.6 \%$, respectively, where contact check accounts for only $9.1 \%$. In areas with good dermatological services, a significantly higher proportion (75.9\%) of cases was detected through dermatological clinics, where voluntary reporting and 'clue survey' were the main modes of detection in endemic areas. As regards confirmation of diagnosis, the great majority of cases were confirmed by leprosy units, even though they were detected in various other situations. Only $6.5 \%$ of leprosy cases were detected and subsequently confirmed by doctors in dermatologic clinics. The present modes of detection and their relation to demographical, epidemiological, clinical factors and health services are discussed. This study emphasizes the cardinal importance of the dermatological clinics in the detection of leprosy cases in China at the present time and hence the need to strengthen the training of doctors in these clinics, while continuously encourage their involvement in leprosy control.
\end{abstract}

\section{Introduction}

Early detection of leprosy patients and timely institution of anti-leprosy treatment are imperative to control and eradicate the disease. It has been observed that along with the

Correspondence to: Xiang-Sheng Chen (e-mail: xschen@jlonline.com, Fax: +86-25-5421813) 
nationwide economic reform initiated in China in the early 1980s and the rapid decrease of the leprosy endemic after the implementation of multi-drug therapy (MDT, the leprosy programme has changed from the vertical to the horizontal and a significant evolution in detection modes of leprosy cases has consequently taken place.

In order to monitor the endemic situation and to provide a useful basis for formulating the leprosy programme, a nationwide registration of newly detected leprosy cases has been undertaken annually since the 1980s in China. The profile of these patients at detection is presented and discussed in this paper.

\section{Materials and methods}

DATA COLLECTION

Data of the study were retrieved from the National System for Leprosy Surveillance ${ }^{1}$, a population-based registry covering the whole country excluding three non-endemic areas, i.e. Beijing, Inner Mongolia and Shanxi as well as Taiwan Province, the Hongkong Special Administrative Region and the Macao Special Administrative Region. All data were collected with the specially designed forms and entered into computer, thus establishing a database for the period 1949-1998. Patients detected during the years 1981-1998 are analysed in the present study.

\section{DETECTION MODES}

Various detection modes have been implemented in China, often with variation over a specific time period. The main modes of detection as follow.

Voluntary reporting: actively and voluntarily reporting the suspected leprosy symptoms by patient himself/herself to medical institutions.

Dermatologic clinic: seeking medical care for skin lesions in dermatological clinic or department of dermatology in general hospital, the lesions having not been considered as leprosy by the patient.

Contact examination: routine examination of leprosy contacts, mainly referring to household contacts.

'Clue survey': group examination based on a specific clue or indication of leprosy, organized by a specialized institution of leprosy control.

Mass survey: systematic population survey, including examination in specific population groups, e.g. school children, etc.

Others: modes other than the above-mentioned, including seeking medical care in department of neurology, etc.

\section{STATISTICAL ANALYSIS}

One-way analysis of variance (ANOVA) and Bonferroni $P$-value were used for comparison of more than two means of quantitative data. Chi-square $\left(\chi^{2}\right)$ test was applied for statistical analysis of categorical data and $\chi^{2}$ test for trend was used for the ordinal categorical data. Data analysis was performed using Epi-Info 5.0 (CDC, Atlanta, GA, USA) and SPSS 8.0 (SPSS Inc., 1989-1997). 


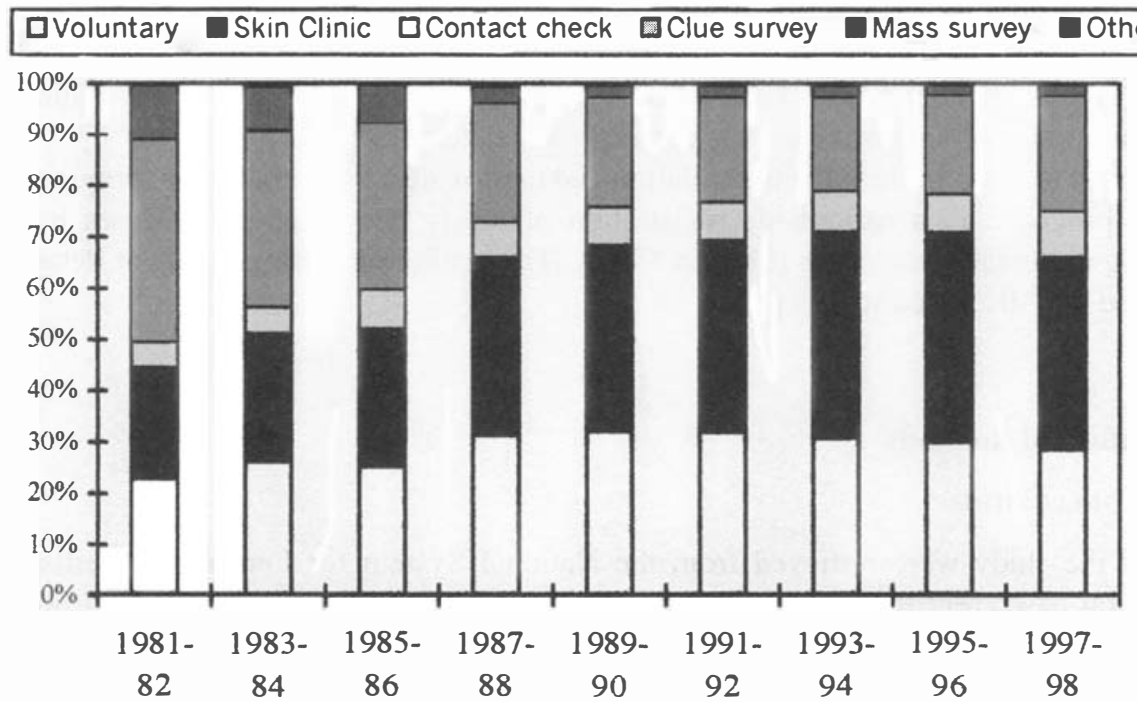

Figure 1. Leprosy cases by different detection methods and time period.

\section{Results}

A total of 31,115 leprosy patients detected during the years 1981-1998 were used to describe the detection methods of leprosy in China. Case detection through voluntary reporting fluctuated year by year, ranging $22.9 \%$ (246/1075) and 32.2\% (1597/4967). During 1981 and 1998, there was an increasing trend in percentage of cases detected through dermatological clinics (21.9-37.3\%) and contact check (4.7-9.1\%), and decreasing trend in the percentage of cases detected through clue survey (39.7-22.5\%) and mass survey (10.6$2 \cdot 1 \%)$. Detection of leprosy cases through dermatological clinic and voluntary reporting have become the main modes of case-finding during 1997-1998, accounting for $37.3 \%$ and $28.6 \%$, respectively, where contact check only accounts for $9.1 \%$ even with an increase in recent years (Figure 1). In addition, 'clue survey' resulted in detecting about $20 \%$ of patients in recent 10 years.

\section{DEMOGRAPHIC CHARACTERISTICS}

More men voluntarily report their disease than women $(31.0 \%$ versus $27.0 \%)$, whereas women are more likely to be detected by family contact survey, $9.8 \%$ being in women and $6.7 \%$ in men. The percentages of detection are not significantly different between men and women in terms of case-findings through dermatological clinics or 'clue survey'. Detection modes in child cases are predominately family contact survey and mass survey, mainly the school survey. Dermatological clinics remain the main mode of detection of leprosy in workers, which is significantly higher than that in farmers even though the dermatological clinics are one of the main modes of detection in farmers. In farmers, the voluntary reporting results in $30.9 \%$ of patients and clue survey in $25.0 \%$. Only $1.6 \%$ of workers and $7.1 \%$ of farmers were detected through contact examination (Table 1). 
Table 1 Leprosy cases by different detection methods and demographic characteristics

\begin{tabular}{|c|c|c|c|c|c|c|c|}
\hline \multirow[b]{2}{*}{$\begin{array}{l}\text { Demographic } \\
\text { characteristics }\end{array}$} & \multicolumn{7}{|c|}{ Numbers and percentages of patients by detection methods } \\
\hline & $\begin{array}{l}\text { No. of } \\
\text { cases }\end{array}$ & $\begin{array}{l}\text { Voluntary } \\
\text { reporting }\end{array}$ & $\begin{array}{l}\text { Dermatology } \\
\text { clinic }\end{array}$ & $\begin{array}{l}\text { Contact } \\
\text { check }\end{array}$ & $\begin{array}{l}\text { Clue } \\
\text { survey }\end{array}$ & $\begin{array}{c}\text { Mass } \\
\text { survey }\end{array}$ & Others \\
\hline \multicolumn{8}{|l|}{ Sex } \\
\hline Male & 22,935 & 7112 & 7998 & 1526 & 5420 & 762 & 117 \\
\hline$(\%)$ & $(100 \cdot 0)$ & $(31 \cdot 0)$ & $(34 \cdot 9)$ & $(6 \cdot 7)$ & $(23.6)$ & $(3 \cdot 3)$ & $(0.5)$ \\
\hline Female & 8180 & 2206 & 2891 & 798 & 1918 & 316 & 51 \\
\hline$(\%)$ & $(100 \cdot 0)$ & $(27 \cdot 0)$ & $(35 \cdot 3)$ & $(9 \cdot 8)$ & (23.4) & (3.9) & $(0.6)$ \\
\hline$\chi^{2}$ test & - & $P<0.01$ & $P>0.05$ & $P<0.01$ & $P>0.05$ & $P<0.05$ & $P>0.05$ \\
\hline \multicolumn{8}{|l|}{ Age* } \\
\hline$<15$ & 1130 & 212 & 248 & 401 & 193 & 74 & 2 \\
\hline (\%) & $(100 \cdot 0)$ & $(18.8)$ & $(21.9)$ & $(35 \cdot 5)$ & $(17 \cdot 1)$ & $(6 \cdot 5)$ & $(0.2)$ \\
\hline $15-29$ & 9957 & 2866 & 3115 & 1138 & 2083 & 314 & 41 \\
\hline (\%) & $(100 \cdot 0)$ & $(30 \cdot 0)$ & $(32.6)$ & $(11.9)$ & $(21 \cdot 8)$ & $(3 \cdot 3)$ & $(0.4)$ \\
\hline $30-49$ & 13,687 & 4418 & 4813 & 552 & 3374 & 456 & 74 \\
\hline$(\%)$ & $(100 \cdot 0)$ & $(32 \cdot 3)$ & $(35 \cdot 2)$ & $(4.0)$ & $(24.7)$ & $(3 \cdot 3)$ & $(0.5)$ \\
\hline $50-$ & 6741 & 1822 & 2713 & 233 & 1688 & 234 & 51 \\
\hline (\%) & $(100 \cdot 0)$ & $(27.0)$ & $(40 \cdot 2)$ & (3.5) & $(25 \cdot 0)$ & (3.5) & $(0 \cdot 8)$ \\
\hline$\chi^{2}$ test & - & $P<0.01$ & $P<0.01$ & $P<0.01$ & $P<0.01$ & $P<0.01$ & $P<0.05$ \\
\hline \multicolumn{8}{|l|}{ Job } \\
\hline Child & 421 & 65 & 128 & 151 & 44 & 33 & 0 \\
\hline$(\%)$ & $(100 \cdot 0)$ & $(15.4)$ & $(30 \cdot 4)$ & $(35.9)$ & $(10 \cdot 5)$ & $(7 \cdot 8)$ & $(0)$ \\
\hline Student & 618 & 144 & 223 & 147 & 67 & 35 & 2 \\
\hline$(\%)$ & $(100 \cdot 0)$ & $(23 \cdot 3)$ & $(36 \cdot 1)$ & $(23 \cdot 8)$ & $(10 \cdot 8)$ & $(5 \cdot 7)$ & $(0 \cdot 3)$ \\
\hline Worker & 1058 & 230 & 627 & 17 & 147 & 24 & 13 \\
\hline$(\%)$ & $(100 \cdot 0)$ & $(21 \cdot 7)$ & $(59.3)$ & $(1 \cdot 6)$ & (13.9) & $(2 \cdot 3)$ & $(1 \cdot 2)$ \\
\hline Farmer & 27,589 & 8528 & 9112 & 1960 & 6884 & 963 & 142 \\
\hline (\%) & $(100 \cdot 0)$ & $(30 \cdot 9)$ & $(33.0)$ & $(7 \cdot 1)$ & $(25 \cdot 0)$ & (3.5) & $(0.5)$ \\
\hline Others & 759 & 159 & 435 & 38 & 112 & 11 & 4 \\
\hline (\%) & $(100 \cdot 0)$ & (20.9) & $(57 \cdot 3)$ & $(5 \cdot 0)$ & $(14 \cdot 8)$ & $(1.4)$ & $(0.5)$ \\
\hline$\chi^{2}$ test & - & $P<0.01$ & $P<0.01$ & $P<0.01$ & $P<0.01$ & $P<0.01$ & $P<0.01$ \\
\hline Unknown & 670 & 192 & 364 & 11 & 84 & 12 & 7 \\
\hline
\end{tabular}

*Age at detection of disease.

\section{Clinical and epidemiological aspects}

The classification of leprosy, the numbers of lesions and nerves and the grading of disabilities according to mode of detection are present in Table 2. More MB patients were detected by voluntary reporting than $\mathrm{PB}$, whereas dermatological clinics resulted in a significantly higher proportion $(38.0 \%)$ of detection in PB patients than in MB $(33.5 \%)$. Voluntary reporting remains the main mode for patients with nerve involvement but without a skin lesion, or with visible disability (WHO grade II), whereas dermatological clinics are more important for the detection of patients with skin lesions but without nerve involvement or disability.

\section{ACCESSIBILITY OF HEALTH SERVICES}

In the cities/counties at different levels, namely provincial capital (PC), prefecture city (PR) and county/township (CT) levels where the accessibility of health services is different, dermatological clinics remain the main mode of detection. However, the voluntary reporting and clue survey resulted in higher proportions in PR and CT levels than in PC level. 
Table 2. Leproy cases by different detection methods and clinical characteristics

\begin{tabular}{|c|c|c|c|c|c|c|c|}
\hline \multirow[b]{2}{*}{$\begin{array}{l}\text { Clinical } \\
\text { features }\end{array}$} & \multicolumn{7}{|c|}{ Numbers and percentages of patients by detection methods } \\
\hline & $\begin{array}{l}\text { No. of } \\
\text { cases }\end{array}$ & $\begin{array}{l}\text { Voluntary } \\
\text { reporting }\end{array}$ & $\begin{array}{l}\text { Dermatology } \\
\text { clinic }\end{array}$ & $\begin{array}{l}\text { Contact } \\
\text { check }\end{array}$ & $\begin{array}{l}\text { Clue } \\
\text { survey }\end{array}$ & $\begin{array}{l}\text { Mass } \\
\text { survey }\end{array}$ & Others \\
\hline \multicolumn{8}{|l|}{ Type } \\
\hline MB & 20,900 & 6757 & 7009 & 1350 & 5018 & 663 & 103 \\
\hline$(\%)$ & $(100 \cdot 0)$ & $(32 \cdot 3)$ & $(33.5)$ & $(6 \cdot 5)$ & $(24 \cdot 0)$ & $(3 \cdot 2)$ & $(0 \cdot 5)$ \\
\hline PB & 10,215 & 2561 & 3880 & 974 & 2320 & 415 & 65 \\
\hline (\%) & $(100 \cdot 0)$ & $(25 \cdot 1)$ & $(38 \cdot 0)$ & (9.5) & $(22 \cdot 7)$ & $(4 \cdot 1)$ & $(0.6)$ \\
\hline $\begin{array}{l}\chi^{2} \text { test } \\
\text { Lesion }\end{array}$ & - & $P<0.01$ & $P<0.01$ & $P<0.01$ & $P<0.05$ & $P<0.01$ & $P>0.05$ \\
\hline None & 1117 & 373 & 311 & 77 & 303 & 41 & 12 \\
\hline$(\%)$ & $(100 \cdot 0)$ & $(33.4)$ & $(27 \cdot 8)$ & $(6 \cdot 9)$ & $(27 \cdot 1)$ & $(3 \cdot 7)$ & $(1 \cdot 1)$ \\
\hline Single & 3171 & 682 & 1134 & 383 & 811 & 144 & 17 \\
\hline$(\%)$ & $(100 \cdot 0)$ & $(21 \cdot 5)$ & $(35 \cdot 8)$ & $(12 \cdot 1)$ & $(25 \cdot 6)$ & $(4 \cdot 5)$ & $(0 \cdot 5)$ \\
\hline Multiple & 26,827 & 8263 & 9444 & 1864 & 6224 & 893 & 139 \\
\hline$(\%)$ & $(100 \cdot 0)$ & $(30 \cdot 8)$ & $(35 \cdot 2)$ & $(6.9)$ & $(23 \cdot 2)$ & (3.3) & $(0.5)$ \\
\hline \multicolumn{8}{|l|}{ Nerve } \\
\hline None & 2494 & 545 & 1139 & 241 & 455 & 107 & 7 \\
\hline$(\%)$ & $(100 \cdot 0)$ & $(21.9)$ & $(45 \cdot 7)$ & (9.7) & $(18 \cdot 2)$ & $(4 \cdot 3)$ & $(0 \cdot 3)$ \\
\hline Single & 10,277 & 2830 & 3814 & 867 & 2353 & 359 & 54 \\
\hline$(\%)$ & $(100 \cdot 0)$ & $(27 \cdot 5)$ & $(37 \cdot 1)$ & $(8 \cdot 4)$ & $(22 \cdot 9)$ & $(3 \cdot 5)$ & $(0 \cdot 5)$ \\
\hline Multiple & 18,344 & 5943 & 5936 & 1216 & 4530 & 612 & 107 \\
\hline (\%) & $(100 \cdot 0)$ & $(32.4)$ & $(32.4)$ & $(6 \cdot 6)$ & (24.7) & (3.3) & $(0.6)$ \\
\hline$\chi^{2}$ test & - & $P<0.01$ & $P<0.01$ & $P<0.01$ & $P<0.01$ & $P>0.05$ & $P>0.05$ \\
\hline \multicolumn{8}{|l|}{ Disability } \\
\hline None & 17,655 & 5205 & 6443 & 1548 & 3797 & 576 & 86 \\
\hline$(\%)$ & $(100 \cdot 0)$ & $(29.5)$ & $(36 \cdot 5)$ & $(8 \cdot 8)$ & $(21 \cdot 5)$ & $(3 \cdot 3)$ & $(0 \cdot 5)$ \\
\hline Grade I & 5071 & 1450 & 2000 & 348 & 1069 & 177 & 27 \\
\hline (\%) & $(100 \cdot 0)$ & $(28 \cdot 6)$ & (39.4) & $(6.9)$ & $(21 \cdot 1)$ & $(3 \cdot 5)$ & $(0 \cdot 5)$ \\
\hline Grade II & 8389 & 2663 & 2446 & 428 & 2472 & 325 & 55 \\
\hline$(\%)$ & $(100 \cdot 0)$ & $(31 \cdot 7)$ & $(29 \cdot 2)$ & $(5 \cdot 1)$ & (29.5) & (3.9) & $(0.7)$ \\
\hline$\chi^{2}$ test & - & $P<0.01$ & $P<0.01$ & $P<0.01$ & $P<0.01$ & $P<0.05$ & $P>0.05$ \\
\hline
\end{tabular}

Consequently, we considered 27 'historical' or present leprosy endemic provinces, municipalities and regions in the mainland as being from two groups according to facilities in dermatologic services at peripheral levels. The group with good facilities included Shanghai, Tianjin, Liaoning, Jiangsu, Shandong, Zhejiang, Fujian and Guangdong. Four provinces and one region, namely Yunnan, Sichuan, Guizhou and Hunan, where there are counties not achieving elimination of leprosy as public health problem, were considered as being endemic areas. In areas with good dermatological services, the majority (75.9\%) of leprosy patients were detected through dermatological clinics, which was significantly higher than that in areas with relatively poor facilities where a significantly higher percentage of patients were detected through either voluntary reporting or 'clue survey'. Similarly, voluntary reporting and 'clue survey' were the main modes of case detection in endemic areas, while more than half the patients in non-endemic areas were found in dermatological clinics (Table 3).

\section{CONFIRMATION OF DIAGNOSIS}

Regardless of the detection modes or areas, the great majority of leprosy cases were 
Table 3. Leprosy cases by different detection methods and areas

Numbers and percentages of patients by detection methods

\begin{tabular}{|c|c|c|c|c|c|c|c|}
\hline $\begin{array}{l}\text { Socio-economic/ } \\
\text { epidemic }\end{array}$ & $\begin{array}{l}\text { No. of } \\
\text { cases }\end{array}$ & $\begin{array}{l}\text { Voluntary } \\
\text { reporting }\end{array}$ & $\begin{array}{l}\text { Dermatology } \\
\text { clinic }\end{array}$ & $\begin{array}{l}\text { Contact } \\
\text { check }\end{array}$ & $\begin{array}{l}\text { Clue } \\
\text { survey }\end{array}$ & $\begin{array}{l}\text { Mass } \\
\text { survey }\end{array}$ & Others \\
\hline \multicolumn{8}{|l|}{ Residence } \\
\hline $\mathrm{PC}$ & 477 & 128 & 307 & 17 & 20 & 4 & 1 \\
\hline$(\%)$ & $(100 \cdot 0)$ & $(26 \cdot 8)$ & $(64.4)$ & $(3.6)$ & $(4 \cdot 2)$ & $(0 \cdot 8)$ & $(0 \cdot 2)$ \\
\hline PR & 3289 & 1036 & 1262 & 255 & 623 & 101 & 12 \\
\hline$(\%)$ & $(100 \cdot 0)$ & $(31 \cdot 5)$ & $(38.4)$ & $(7 \cdot 8)$ & $(18.9)$ & $(3 \cdot 1)$ & $(0 \cdot 4)$ \\
\hline CL & 27,349 & 8154 & 9320 & 2052 & 6695 & 973 & 155 \\
\hline$(\%)$ & $(100 \cdot 0)$ & $(29.8)$ & $(34 \cdot 1)$ & $(7 \cdot 5)$ & $(24 \cdot 5)$ & $(3 \cdot 6)$ & $(0 \cdot 6)$ \\
\hline$\chi^{2}$ test & - & $P<0.05$ & $P<0.01$ & $P<0.01$ & $P<0.01$ & $P<0.01$ & $p>0.05$ \\
\hline \multicolumn{8}{|l|}{ Good facility* } \\
\hline Yes & 6407 & 905 & 4864 & 153 & 319 & 79 & 87 \\
\hline$(\%)$ & $(100 \cdot 0)$ & $(14 \cdot 1)$ & $(75.9)$ & $(2 \cdot 4)$ & $(5 \cdot 0)$ & $(1 \cdot 2)$ & $(1.4)$ \\
\hline No. & 24,708 & 8413 & 6025 & 2171 & 7019 & 999 & 81 \\
\hline$(\%)$ & $(100 \cdot 0)$ & $(34 \cdot 0)$ & $(24 \cdot 4)$ & $(8 \cdot 8)$ & $(28 \cdot 4)$ & $(4 \cdot 0)$ & $(0 \cdot 3)$ \\
\hline$\chi^{2}$ test & - & $P<0.01$ & $P<0.01$ & $P<0.01$ & $P<0.01$ & $P<0.01$ & $P<0.01$ \\
\hline \multicolumn{8}{|l|}{ Endemic } \\
\hline Yes & 16,981 & 6390 & 3148 & 1693 & 5087 & 631 & 32 \\
\hline$(\%)$ & $(100 \cdot 0)$ & $(37.6)$ & $(18.5)$ & $(10 \cdot 0)$ & $(30 \cdot 0)$ & $(3 \cdot 7)$ & $(0 \cdot 2)$ \\
\hline No & 14,134 & 2928 & 7741 & 631 & 2251 & 447 & 136 \\
\hline$(\%)$ & $(100 \cdot 0)$ & $(20 \cdot 7)$ & $(54 \cdot 8)$ & (4.5) & $(15 \cdot 9)$ & $(3 \cdot 2)$ & $(1 \cdot 0)$ \\
\hline$\chi^{2}$ test & - & $P<0.01$ & $P<0.01$ & $P<0.01$ & $P<0.01$ & $P<0.01$ & $P<0.01$ \\
\hline
\end{tabular}

*Areas with good facilities in dermatological services at peripheral levels.

confirmed by leprosy units. A significantly higher proportion of confirmation by leprosy units was found in the areas without good facilities of dermatological services or with an endemic situation (Table 4). In areas with good facilities or without an endemic situation, confirmation by dermatological clinics accounted for $4.4 \%$ and $4.7 \%$, respectively. Only $6.5 \%$ of leprosy

Table 4. Leprosy cases by confirmation units, facilities and endemic situation

\begin{tabular}{|c|c|c|c|c|c|}
\hline & \multicolumn{5}{|c|}{ Numbers of patients by confirmation units } \\
\hline & $\begin{array}{c}\text { Number of } \\
\text { cases }\end{array}$ & $\begin{array}{l}\text { Leprosy } \\
\text { unit }\end{array}$ & $\begin{array}{l}\text { Primary } \\
\text { clinic }\end{array}$ & $\begin{array}{l}\text { Dermatology } \\
\text { department }\end{array}$ & Others* \\
\hline \multicolumn{6}{|c|}{ Good facility* } \\
\hline Yes & 6407 & 6025 & 77 & 282 & 23 \\
\hline (\%) & $(100 \cdot 0)$ & $(94 \cdot 0)$ & $(1 \cdot 2)$ & $(4.4)$ & $(0.4)$ \\
\hline No & 24,708 & 23,850 & 213 & 575 & 70 \\
\hline$(\%)$ & $(100 \cdot 0)$ & $(96 \cdot 5)$ & $(0 \cdot 9)$ & $(2 \cdot 3)$ & $(0 \cdot 3)$ \\
\hline$\chi^{2}$ test & - & $P<0.01$ & $P<0.01$ & $P<0.01$ & $P<0.01$ \\
\hline \multicolumn{6}{|l|}{ Endemic } \\
\hline Yes & 16,981 & 16,701 & 69 & 191 & 20 \\
\hline (\%) & $(100 \cdot 0)$ & $(98.4)$ & $(0.4)$ & $(1 \cdot 1)$ & $(0 \cdot 1)$ \\
\hline No & 14,134 & 13,174 & 221 & 666 & 73 \\
\hline$(\%)$ & $(100 \cdot 0)$ & $(93 \cdot 2)$ & $(1 \cdot 6)$ & (4.7) & $(0 \cdot 5)$ \\
\hline$\chi^{2}$ test & - & $P<0.01$ & $P<0.01$ & $P<0.01$ & $P<0.01$ \\
\hline
\end{tabular}

*Areas with good facilities in dermatologic services at peripheral levels. 
Table 5. Leprosy cases by confirmation units and detection methods

\begin{tabular}{|c|c|c|c|c|c|c|}
\hline \multirow[b]{2}{*}{ Detection methods : } & \multicolumn{6}{|c|}{ Numbers and percentages of patients by confirmation units } \\
\hline & $\begin{array}{l}\text { No. of } \\
\text { cases }\end{array}$ & $\begin{array}{l}\text { Leprosy } \\
\text { unit }\end{array}$ & $\begin{array}{l}\text { Primary } \\
\text { clinic }\end{array}$ & $\begin{array}{c}\text { Dermatology } \\
\text { department }\end{array}$ & Others* & $\begin{array}{c}\text { Delay } \\
(\text { mean } \pm S D)^{* *}\end{array}$ \\
\hline Voluntary reporting & 9318 & 9013 & 121 & 144 & 40 & $3.58 \pm 5.99$ \\
\hline (\%) & $(100 \cdot 0)$ & $(96 \cdot 7)$ & $(1 \cdot 3)$ & $(1 \cdot 5)$ & $(0 \cdot 4)$ & - \\
\hline Dermatology clinic & 10,889 & 10160 & 0 & 706 & 23 & $2 \cdot 89 \pm 5 \cdot 30$ \\
\hline (\%) & $(100 \cdot 0)$ & $(93 \cdot 3)$ & $(0 \cdot 0)$ & $(6 \cdot 5)$ & $(0 \cdot 2)$ & - \\
\hline Contact check & 2324 & 2311 & 13 & 0 & 0 & $2.86 \pm 8.28$ \\
\hline$(\%)$ & $(100 \cdot 0)$ & $(99.4)$ & $(0 \cdot 6)$ & $(0 \cdot 0)$ & $(0 \cdot 0)$ & - \\
\hline 'Clue survey' & 7338 & 7201 & 137 & 0 & 0 & $5 \cdot 23 \pm 7 \cdot 84$ \\
\hline$(\%)$ & $(100 \cdot 0)$ & $(98 \cdot 1)$ & $(1.9)$ & $(0 \cdot 0)$ & $(0 \cdot 0)$ & - \\
\hline Mass survey & 1078 & 1071 & 7 & 0 & 0 & $5.49 \pm 9.43$ \\
\hline$(\%)$ & $(100 \cdot 0)$ & (99.4) & $(0 \cdot 6)$ & $(0 \cdot 0)$ & $(0 \cdot 0)$ & - \\
\hline Others & 168 & 139 & 12 & 7 & 10 & $3.95 \pm 5.34$ \\
\hline$(\%)$ & $(100 \cdot 0)$ & $(82 \cdot 7)$ & $(7 \cdot 1)$ & $(4 \cdot 2)$ & $(6 \cdot 0)$ & - \\
\hline$\chi^{2}$ test & - & $P<0.01$ & $P<0.01$ & $P<0.01$ & $P<0.01$ & - \\
\hline Total & 31,115 & 29,895 & 290 & 857 & 73 & $3 \cdot 34 \pm 6.66$ \\
\hline$(\%)$ & $(100 \cdot 0)$ & $(96 \cdot 0)$ & $(0.9)$ & $(2 \cdot 8)$ & $(0 \cdot 3)$ & - \\
\hline
\end{tabular}

*Mainly including confirmation by department of neurology.

**ANOVA of mean delay of detection $(F=136.0, P<0.001)$; statistically significant different between modes of detection except dermatological clinics versus contact check, 'clue survey' versus mass survey, and others versus any other mode.

cases were detected and consequently confirmed by doctors in dermatological clinics, and another $4.2 \%$ were detected by other doctors, mainly neurologists and then confirmed by dermatologists (Table 5).

\section{DELAY IN DETECTION}

For all the cases detected during 1981 and 1998, the overall mean delay in detection is $3 \cdot 3 \pm$ 6.7 years. Clue survey and mass survey are two mode of detection with a significant higher delay in detection than voluntary reporting, dermatological clinics or contact check. Delay in detection of leprosy cases through dermatological clinics was comparable with contact check, and significantly shorter than other modes of detection (Table 4).

\section{Discussion}

Besides importance for control of leprosy, early detection of the disease is essential to prevent deformities and disabilities. Modes of detection of leprosy patients can be classified in several categories: systematic population survey, voluntary reporting, surveys of specific population groups, surveillance of high-risk groups, and combined multi-disease detection and care. It should be stressed that there is no leprosy control without organized detection. ${ }^{2}$ Leprosy has been successfully controlled in China through continued efforts for more than 40 years. ${ }^{3}$ During this period, three systematic population surveys in 1958, 1965 and 1972 were carried out in the country which have played an important role in detection of leprosy patients, especially the backlog of patients. However, such a method cannot be recommended for 
the present situation in China because it is time-consuming and expensive, resulting in poor cost-effectiveness, although it still has its place in prevalence surveys. ${ }^{2}$

During the study period, detection of cases through contact examination and mass survey accounted for only $7.5 \%$ and $3.5 \%$, respectively, much lower figures than those observed in some leprosy endemic areas. ${ }^{4,5}$ Moreover, the proportion of patients detected by "clue survey' and mass survey have significantly decreased through the years, which may be mainly due to the decreasing application or insensitivity of these two methods in the recent years. However, the dermatological services remained the main mode of case detection and significantly increased year by year, understanding the importance of dermatological clinics in case-finding. In China, especially in endemic areas, some doctors in dermatological clinics have shown increasing interest in leprosy and many dermatologists are now willing to be involved in leprosy control. ${ }^{6}$ However, some operational factors may also affect the high detection in these clinics, such as incentives which may encourage doctors to bring forward the suspected patients, including those in whom over- or wrong diagnosis may be a possibility. This can be supported by the fact that only $6.5 \%$ of leprosy patients detected through dermatological clinics were confirmed by themselves. Taking these points into consideration, further professional training on leprosy should be provided to doctors in dermatological clinics while continuously encouraging their involvement in leprosy control.

The proportion of voluntary reporting in the present study (29.9\%) was comparable with that observed during 1995-1997 in Khulna, Bangladesh, where it accounted for 33\%, but the proportion found by contact examination in our study is much less than that in the latter. ${ }^{7}$ In India, more women were detected by general survey and contact survey, while the proportion of detection by referral, voluntary reporting and school survey among women was less than among men. ${ }^{8}$ In the present study, the difference between men and women was not found in detection modes of dermatological clinic and clue survey, but men were more likely to voluntarily come forward and women to be detected by contact examination, which is similar to that observed in Khulna of Bangladesh. ${ }^{7}$ This may be due to the fact that in the countryside, especially the endemic areas, the men usually leave home to go out to work and have less chance of being examined and are more likely to voluntarily report the disease if any symptom or sign occurs. The proportion of dermatological clinic cases in younger age groups was significantly lower than that in elder age groups, and in the farmers it was lower than in other workers. The association of lower proportion with specific age groups and jobs could be related to the finding that children tend to be detected through contact survey, ${ }^{9}$ and farmers have a lower accessibility to hospitals, including dermatological clinics.

More patients with MB leprosy and/or visible disability were detected by voluntary reporting as compared to patients with PB and/or without visible disability. This obviously implies that the MB lesions and/or visible disability were easily noted by patients themselves and voluntarily brought forward. It is interesting that through dermatological clinics the patients with PB leprosy and/or without nerve involvement or visible disability can be detected to a greater extent of $38 \%, 45 \%$ and $39.4 \%$, respectively.

It is found from this study that there were differences in detection modes between the patients from different areas in terms of resident levels, health service facilities and endemic situations. The differences may be related to accessibility of health services and implementation of leprosy control programs in specific areas. This implies that the detection modes should be adapted appropriately and that health education should be strengthened according to the specific situation at the local level. 
It was interesting to find that delay duration in detection of cases through dermatological clinics was comparable with clue survey, and significantly shorter than other modes of detection, including voluntary reporting and mass survey. It is known that the early detection of leprosy in China does not depend upon active case-detection. Notification of cases through dermatological clinics has been a good method of case-finding, which not only detected cases relatively soon after have become symptomatic but also before most have developed grade-II disability. ${ }^{10}$

Based upon the present study, it has been known that there has been a significant evolution of detection modes during the past years. Through these modes, a total of about 1800 leprosy patients have been detected annually in China in recent years. However, the Leprosy Elimination Campaign (LEC) carried out recently in some leprosy endemic areas has shown that the actual number of leprosy patients was significantly higher than reported figures, including multibacillary cases, suggesting that our present detection modes are not sensitive enough to find out the leprosy cases, at least in the endemic areas.

\section{Acknowledgements}

This study was a nationwide investigation supported and organized by the Ministry of Health of China. We thank the leprosy workers in the institutions of dermatology at provincial and county levels of 27 provinces, municipalities and regions in the country for their excellent assistance in data collection.

\section{References}

${ }^{1}$ Chen X-S, Li W-Z, Jiang C et al. Computerization of leprosy records: National Leprosy Recording and Reporting System in China. Lepr Rev, 2000; 71: 47-56.

2 Lechat MF. Control programs in leprosy. In: Hastings RC (ed) Leprosy. Churchill Livingstone, Edinburgh, 1985, pp. 253-268.

3 Chen X-S, Li W-Z, Cheng J et al. Leprosy in China: epidemiological tends between 1949 and 1998. Bulletin of World Health Organization, 2001, in press.

${ }^{4}$ Saylan $\mathrm{T}$ et al. The characteristics and mode of detection of the new patients encountered in the leprosy endemic province of Van within the last five years. Ind J Lepr, 1989; 61: 225-228.

5 Ganapati R et al. Leprosy detection through non-survey techniques. Ind J Lepr, 1984; 56: 622-625.

6 Chen X-S et al. An investigation of attitudes, beliefs and behaviour of leprosy patients, family members and PHC workers towards multidrug therapy in Yangzhou and Dongtai Districts of China. Lepr Rev, 1997; 68: $155-161$.

7 Ishida Y et al. Detection mode of leprosy and its disability grading in Khulna City, Bangladesh. Jpn J Lepr, 1998; 66: 391-400.

${ }^{8}$ Grand AL. Women and leprosy: a review. Lepr Rev, 1997; 68: 203-211.

9 Chen X-S, Li W-Z, Cheng J et al. Leprosy in children: a retrospective study in China, 1986-1997. J Trop Pediatr, 2000; 46: 207-211.

${ }^{10}$ Chen X-S, Li W-Z, Cheng J et al. Leprosy in China: delay in the detection of cases. Ann Trop Med Parasitol, 2000; 94: 181-188. 